\title{
Reaching high-risk underserved individuals for cancer genetic counseling by video-teleconferencing
}

\author{
Lindsey A Mette, MS, MPH, ${ }^{\text {ab }}$ Anna María Pulido Saldívar, MPH, ${ }^{\text {bc }}$ Natalie E Poullard, \\ MA, MS, ${ }^{\text {ab }}$ Ivette C Torres, BA, ${ }^{\text {bd }}$ Sarah G Seth, MS, MPH, ${ }^{\text {ab }}$ Brad H Pollock, PhD, \\ $\mathrm{MPH},{ }^{\text {ef }}$ and Gail E Tomlinson, $\mathrm{MD}, \mathrm{PhD}^{\text {abf }}$
}

\begin{abstract}
${ }^{a}$ Department of Pediatrics and ${ }^{b}$ Greehey Children's Cancer Research Institute, University of Texas Health Science Center at San Antonio; 'Laredo Regional Campus (University of Texas Health Science Center at San Antonio), Laredo, Texas; ${ }^{\mathrm{d}}$ Regional Academic Health Center at Harlingen (University of Texas Health Science Center at San Antonio), Harlingen, Texas; ${ }^{\mathrm{e} D e p a r t m e n t}$ of Public Health Sciences, University of California-Davis, Davis, California; and ${ }^{\mathrm{f} C a n c e r}$ Therapy and Research Center, University of Texas Health Science Center at San Antonio
\end{abstract}

Background Breast and colorectal cancers are common cancers for which genetic risk assessment and counseling are available. However, these services are often limited to metropolitan areas and are not readily accessible to underserved populations. Moreover, ethnic and racial disparities present additional obstacles to identifying and screening high-risk individuals and have a bearing on treatment outcomes.

Objective To provide cancer genetic risk assessment and counseling through telemedicine to the remote, underserved primarily Hispanic population of the Texas-Mexico border region.

Methods Program participants were mailed a questionnaire to assess their satisfaction with the program so that we could determine the acceptability of video-teleconferencing for cancer risk assessment.

Results The overall level of satisfaction with the program was very high, demonstrating the acceptability of a cancer genetic risk assessment program that relied on telemedicine to reach and underserved minority community.

Limitations Delivery model requires the availability of and access to communication technologies; trained staff are needed at remote sites for sample collection and patient handling.

Conclusion Video-teleconferencing is an acceptable method of providing cancer risk assessment in a remote, underserved population.

Funding Supported primarily by a grant from the Cancer Prevention and Research Institute of Texas (PP120089 [GT]), NIH-NCI P30 CA54174 (CTRC at UTHSCSA); and a grant from the Valley Baptist Legacy Foundation.

$\mathrm{B}$ reast cancer is the most common cancer in women across all races and the leading cause of cancer-related death in Hispanic women in the United States, which warrants its classification as a public health concern. ${ }^{1}$ Hispanic women have a lower overall lifetime risk of breast cancer compared with non-Hispanic white women (9.0\% vs $13.8 \%$, respectively), however there are disparities between the 2 groups in diagnosis and treatment outcomes. ${ }^{2}$ Similar to other public health issues, social determinants of health contribute to the disparities in the diagnosis, treatment, and survival of breast cancer. Compared with their nonHispanic white counterparts, Hispanic women are less likely to have received a screening mammogram within the past year, are more likely to be diagnosed with breast cancer at a later stage, experience a longer time from diagnosis to treatment, have greater disruptions in breast cancer treatment, and have a higher mortality rate from the disease..$^{3-6}$

Lynch syndrome, the most common hereditary colon cancer predisposition, accounts for $2 \%-4 \%$ of colorectal cancer. ${ }^{7}$ It is recommended that individuals with Lynch syndrome or a family history of colorectal cancer increase the frequency of their screening colonoscopy and start screening at an earlier age. ${ }^{8}$ Numerous factors influence the completion of recommended colonoscopy screenings, including physician referral and socioeconomic status. Among individuals with a first-degree relative affected with colorectal cancer, Hispanic men and women are $31 \%$ less likely to have received a colonoscopy in the

Accepted for publication February 2, 2016. Correspondence: Gail E Tomlinson, MD, PhD; tomlinsong@uthscsa.edu. Disclosures: The authors report no conflicts of interest. JCSO 2016;14:1 162-168. (2016 Frontline Medical Communications. doi: 10.12788 /jicso.0247. 
previous 5 years, compared with whites. ${ }^{9}$ Minority status, recent immigrant status, low income, low education, and residing in a non-urban area are all predictors of lower rates of colorectal cancer screening. ${ }^{9-11}$

Access to services for genetic risk assessment and counseling is often limited to major metropolitan areas. The border region of South Texas is a medically underserved area, especially with regard to cancer genetics. In addition, it is distinct in comparison with the state of Texas and the nation as a whole, because the population is primarily Hispanic and rapidly growing, and poverty and illiteracy rates are significantly higher than elsewhere in the state and rest of the nation (Figure 1)..$^{12,13}$ Furthermore, for reasons that are not yet clear, Hispanic women in South Texas have a higher incidence of breast cancer compared with Hispanic women elsewhere in Texas (83.5 vs 74.8 cases per 100,000, respectively). ${ }^{14}$ The incidence of colorectal cancer in Hispanics is slightly higher in South Texas than in the state overall. ${ }^{14}$ There is also a gender disparity in the incidence of colorectal cancer among Hispanics in the South Texas region, with men being diagnosed at a rate of 1.59 times that of women (52.5 vs 33 cases per 100,000 , respectively). ${ }^{14}$

With almost $10 \%$ of breast and colorectal cancer incidence attributable to a hereditary predisposition, genetic risk assessment for cancer has become the standard of care in the oncology and primary care settings. ${ }^{15}$ The US Preventative Services Task Force supports genetic counseling and risk assessment (GCRA) for women with family histories of breast or ovarian cancer. ${ }^{16}$ GCRA involves the analysis of personal and family medical histories, educating patients on cancer risks and prevention, and nondirective discussion of genetic testing and possible interventions for mutation carriers. The United States Preventative Services Task Force has concluded that genetic counseling reduces cancer worry, anxiety, and depression and increases the accuracy of cancer risk perception and decreasing intention for mutation testing. ${ }^{16}$ For example, for patients who are undergoing treatment for breast or ovarian cancer, identification of a $B R C A$ mutation may guide chemotherapy decisions. ${ }^{17,18}$

Socioeconomic and demographic factors present multiple challenges for the delivery of health care and preventive medicine, many of which are prevalent among minor- ity populations. Compared with white women, Hispanic and Asian women have lower levels of awareness of genetic testing for breast cancer risk. ${ }^{19,20}$ Those who are aware of the availability of genetic testing are more likely to experience competing life distracters that prevent them from gaining access to GCRA. ${ }^{21}$ Adding to these barriers in South Texas

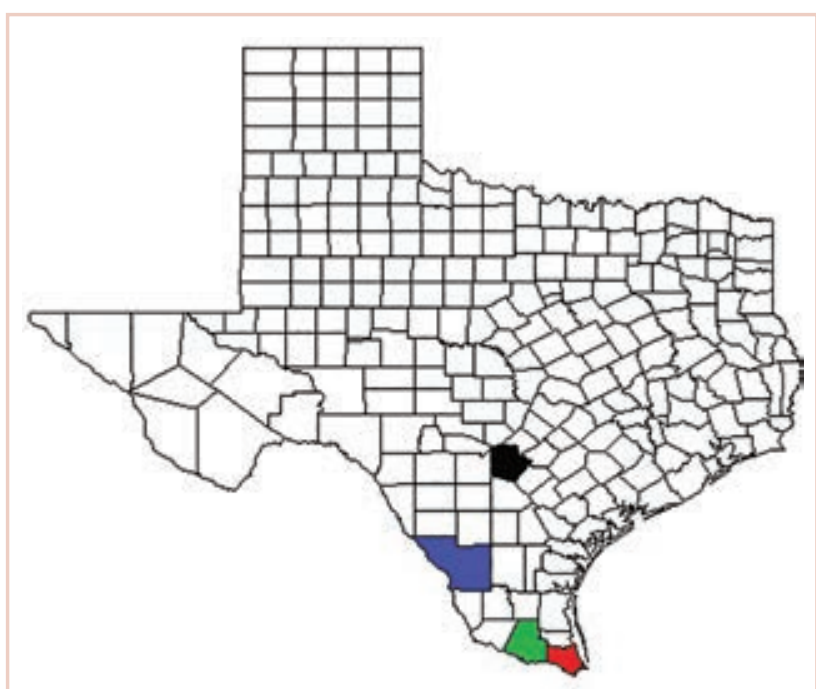

FIGURE 2 Program geographic region. Participants were seen at one of the regional campuses: UT Health Science Center at San Antonio, Bexar County (black), Laredo Regional Campus, Webb County (blue), McAllen Family Medicine Residency Program, Hidalgo County (green), or Regional Academic Health Center, Cameron County (red). 
is the patient's distance from an interdisciplinary academic cancer center, a limited proficiency in English, the fragmentation of families and medical care across the international border, a lack of socioeconomic and health care resources and health insurance, and distrust of and a lack of familiarity with the US medical system.

\section{Project design and methods}

We established an outreach education and service program administered by the University of Texas Health Science Center at San Antonio at its 4 clinical sites serving Bexar, Cameron, Hidalgo, and Webb counties in South Texas in an effort to decrease disparities in access to genetic services and promote genetic risk assessment and education among health care providers and community members in the region (Figure 2). The clinical sites were in a region in which most of the patients were of Hispanic background and where a large proportion of individuals were uninsured or underinsured.

Health care providers in oncology and primary care settings were made aware of our program through individual office visits by program staff, presentations at hospital grand rounds, or provision of written information about the program. Program participants who were in need of services were either directly referred by health care providers and county health clinics, or were self-referred after receiving program information through various outreach activities. Family history questionnaires were reviewed by trained program staff for appropriate candidates for formal GCRA. Participants at high risk based on their personal and/or family medical histories were contacted by program staff in the clinical sites for an initial telephone screening. Those who met the National Comprehensive Cancer Network (NCCN) guidelines for genetic counseling and were interested in our clinical genetics services were scheduled to meet with a certified genetic counselor or oncologist experienced in cancer genetic risk assessment at one of our clinical sites for either an in-person appointment or one conducted through video-teleconferencing. The initial visit included genetic risk assessment, pedigree construction, and tailored education regarding cancer risk factors and genetics. The one-on-one session was conducted through a private, secured telecommunication service between the originating site and the regional extension site. Providers also traveled to distant sites about once a month for in-person GCRA sessions. They split their time among 4 clinical sites, so patients had no input regarding the type of appointment provided (video-teleconferencing or in-person). As a result, there were no measurable differences in patient accrual percentages between the service delivery models. Participants who met genetic testing criteria were offered genetic testing; those who underwent genetic testing were seen for a follow-up visit, also by video-teleconferencing, for result disclosure and further risk assessment.
To evaluate overall satisfaction with the video-teleconferencing model compared with the in-person service delivery model and measure the outcomes of undergoing genetic risk assessment, the Genetic Counseling Satisfaction Scale and previously used survey instruments for patient satisfaction in telegenetic counseling were adapted, translated into Spanish, and revised so that they would be accessible to individuals with a low reading level. ${ }^{22,23}$ The Spanish version of the survey was reviewed by native Spanish speakers, both within the program and in the community. The survey assessed participant demographics, overall satisfaction with GCRA and provider, patient comfort during the session, ability to understand the information provided, perceived benefit of GCRA, and self-assessment of cancer risk after counselling. The questions on participant satisfaction and health beliefs were measured on a 5-point Likert-type scale.

Participants who attended at least one genetic counseling visit between June 1, 2012 and October 31, 2014 were eligible for inclusion in the survey. All participants who met inclusion criteria were mailed a 20 -item questionnaire in Spanish and English. Before the mailings, each participant was called by a team member to verify the mailing address, notify them that the questionnaire would be arriving and what its purpose was, and inquire about changes in healthrelated behaviors. Completed surveys were returned in self-addressed, stamped envelopes that had been provided to the participants. Each returned survey was recorded for summary of overall satisfaction level and collection of open-text responses. Survey responses were anonymous because no specific patient identifiers were included on the questionnaire.

\section{Results}

Program participants were contacted by telephone before survey distribution to determine if they had made any behavioral modifications after they received their genetic risk assessments. More than a third (34\%) of those contacted affirmed they had made a change in lifestyle and/ or increased screening frequency (38\%). Of the 353 surveys distributed, 119 were returned completed for a completion rate of $34 \%$. Five were returned without a forwarding address, and 1 participant was found to have died. The distribution between service delivery models was comparable, with $53 \%$ of participants seen in-person and $47 \%$ being seen through video-teleconferencing. Most survey respondents ( $\mathrm{n}=95,80 \%)$ had undergone genetic testing. Most were aged 50 years or older $(n=69$, $58 \%)$, Hispanic $(\mathrm{n}=67,56 \%)$, primarily English speaking $(\mathrm{n}=100,84 \%)$, lived in Cameron/Hidalgo counties $(n=63,53 \%)$, had some college education $(n=81$, $68 \%$ ), and had an annual household income of less than $\$ 50,000(\mathrm{n}=47,39.5 \%)$. The respondent characteristics are shown in Table 1. 
TABLE 1 Summary of respondent characteristics ( $N=119)$

\begin{tabular}{lc} 
Characteristic & $\begin{array}{c}\text { Respondents, } \\
\text { n (\%) }\end{array}$ \\
\hline Appointment type & $63(52.9)$ \\
In person & $56(47.1)$ \\
Telemedicine & \\
Use of translator & $17(14.3)$ \\
Yes, staff & $2(1.7)$ \\
Yes, family & $100(84)$ \\
No & \\
Genetic testing & $95(79.8)$ \\
Yes, genetic testing performed & $23(19.3)$ \\
No, genetic testing not performed & $1(0.8)$ \\
No answer
\end{tabular}

Participant's perceived chance of getting cancer

Higher than previously thought

$13(10.9)$

Same as previously thought

$29(24.4)$

Lower than previously thought

$58(48.7)$

I don't know

$19(16)$

Primary source of health information

Physician

$47(40.9)$

Internet

18 (15.7)

Friends or family

$14(12.2)$

Magazines/Newspapers

14 (12.2)

Health Fairs

$10(8.7)$

Television

$9(7.8)$

Other

$3(2.6)$

\section{Age, y}

20-29

30-39

$1(0.8)$

40-49

17 (14.3)

$31(26.1)$

50-59

$36(30.3)$

60-69

22 (18.5)

70-79

$10(8.4)$

$80+$

$1(0.8)$

No response

$1(0.8)$

Race/ethnicity

Hispanic

67 (56.3)

White

$46(38.7)$

African American

2 (1.7)

Ashkenazi

$1(0.8)$

Other

$1(0.8)$

No answer

2 (1.7)

Level of education

$\leq 6$ th grade

7-9th grade

10-12th grade

Some college

College

Post graduate

$6(5.0)$

$12(10.1)$

14 (1 1.8)

$34(28.6)$

23 (19.3)

$24(20.2)$

No answer

\begin{tabular}{|lc|}
\hline TABLE 1 / continued & $\begin{array}{c}\text { Respondents, } \\
\text { n (\%) }\end{array}$ \\
Characteristic & $18(15.1)$ \\
Annual household income, US \$ & $14(11.8)$ \\
$<15,000$ & $6(5.0)$ \\
$15,000-24,999$ & $9(7.6)$ \\
$25,000-34,999$ & $18(15.1)$ \\
$35,000-44,999$ & $7(5.9)$ \\
$50,000-74,999$ & $17(14.3)$ \\
$75,000-99,999$ & $30(25.2)$ \\
$100,000+$ & \\
Prefer not to answer & $63(53)$ \\
Nearest city (in South Texas region) & $14(12)$ \\
Harlingen-McAllen & $42(35)$ \\
Laredo & \\
San Antonio &
\end{tabular}

For questions about the quality of the clinical services, survey respondents were highly satisfied with the session and the provider, with an overall rating of 4.715 out of 5 (Table 2). The service delivery model was not associated with a difference in participant satisfaction. Most of the survey respondents reported a decrease in their concerns about developing cancer after they received genetic counseling ( $\mathrm{n}=58,49 \%)$. Each survey respondent could provide open-text answers to questions on aspects of the program they found helpful, as well as suggestions for improvement. Of the 62 respondents who addressed the strengths of the program, the most frequent comment was an appreciation of the service providers and staff involved with the program $(n=23,37 \%)$. Close to a third of respondents ( $n=20,32 \%)$ expressed gratitude or appreciated the information received during the appointment $(\mathrm{n}=18,29 \%)$. The remaining responses described respondents' satisfaction with the program and their feeling comfortable during the appointment or at ease during the session. The responses also indicated that respondents found the program valuable and thought it was professional, appreciated the time and attention they received, thought communication effective, and appreciated the ease of scheduling and telemedicine as a means of service delivery.

Of the 61 respondents who provided suggestions on how to improve the program, the most frequent answer was Nothing, the program is great $(\mathrm{n}=25,41 \%)$. Other suggestions by more than 1 respondent included improved advertising and outreach, shorter waiting times for appointments, continuing with the program, provision of additional services, simplifying the referral process, and assisting with insurance reimbursement or obtaining insurance. Suggestions to offer participation in research, require less family history information, and spend more 
TABLE 2 Survey responses for items addressing respondent level of satisfaction with genetic counseling session by in-person (P) or video-teleconferencing (V) participation

Level of satisfaction (1-5), n (\%)

\begin{tabular}{|c|c|c|c|c|c|c|c|}
\hline Item & $\begin{array}{l}\text { Strongly } \\
\text { Agree, } 5\end{array}$ & Agree, 4 & Neutral, 3 & Disagree, 2 & $\begin{array}{c}\text { Strongly } \\
\text { disagree, } 1\end{array}$ & $\begin{array}{c}\text { No answer, } \\
n(\%)\end{array}$ & $\begin{array}{l}\text { Average } \\
\text { Score [SD] }\end{array}$ \\
\hline $\begin{array}{l}\text { I felt the genetic counselor/ } \\
\text { doctor listened to me }\end{array}$ & $\begin{array}{l}\text { P } 48(76) \\
\text { V } 45(82)\end{array}$ & $\begin{array}{c}15(24) \\
9(16)\end{array}$ & $\begin{array}{l}0(0) \\
0(0)\end{array}$ & $\begin{array}{l}0(0) \\
0(0)\end{array}$ & $\begin{array}{l}0(0) \\
1(2)\end{array}$ & $\begin{array}{l}0(0) \\
0(0)\end{array}$ & $\begin{array}{c}4.76[0.43] \\
4.76[0.63]\end{array}$ \\
\hline $\begin{array}{l}\text { I felt the genetic counselor/ } \\
\text { doctor took me seriously }\end{array}$ & $\begin{array}{l}\text { P } 50 \text { (79) } \\
\text { V } 46(84)\end{array}$ & $\begin{array}{c}12(19) \\
8(15)\end{array}$ & $\begin{array}{l}0(0) \\
1(2)\end{array}$ & $\begin{array}{l}\mathbf{0}(\mathbf{0}) \\
0(0)\end{array}$ & $\begin{array}{l}0(0) \\
1(2)\end{array}$ & $\begin{array}{l}\mathbf{0}(\mathbf{0}) \\
0(0)\end{array}$ & $\begin{array}{c}4.73[0.40] \\
4.84[0.68]\end{array}$ \\
\hline $\begin{array}{l}\text { There was enough time to } \\
\text { discuss all of my concerns } \\
\text { and questions }\end{array}$ & $\begin{array}{l}\text { P } 46(73) \\
\text { V } 43(78)\end{array}$ & $\begin{array}{l}12(19) \\
11(20)\end{array}$ & $\begin{array}{l}4(6) \\
1(2)\end{array}$ & $\begin{array}{l}1(2) \\
0(0)\end{array}$ & $\begin{array}{l}0(0) \\
0(0)\end{array}$ & $\begin{array}{l}0(0) \\
0(0)\end{array}$ & $\begin{array}{c}4.63[0.69] \\
4.76[0.48]\end{array}$ \\
\hline $\begin{array}{l}\text { I understood the informa- } \\
\text { tion provided during my } \\
\text { appointment }\end{array}$ & $\begin{array}{l}\text { P } 43(\mathbf{6 8 )} \\
\vee 43(78)\end{array}$ & $\begin{array}{l}17(\mathbf{2 7}) \\
11(20)\end{array}$ & $\begin{array}{l}3(5) \\
0(0)\end{array}$ & $\begin{array}{l}\mathbf{0}(\mathbf{0}) \\
0(0)\end{array}$ & $\begin{array}{l}0(0) \\
0(0)\end{array}$ & $\begin{array}{l}\mathbf{0}(\mathbf{0}) \\
0(0)\end{array}$ & $\begin{array}{c}\mathbf{4 . 6 3}[\mathbf{0 . 5 8}] \\
4.76[0.48]\end{array}$ \\
\hline $\begin{array}{l}\text { The information provided } \\
\text { during my appointment } \\
\text { helped me make decisions } \\
\text { about my health }\end{array}$ & $\begin{array}{l}\text { P } 47(75) \\
\vee 38(69)\end{array}$ & $\begin{array}{l}9(14) \\
13(24)\end{array}$ & $\begin{array}{c}6(10) \\
3(5)\end{array}$ & $\begin{array}{l}1(2) \\
0(0)\end{array}$ & $\begin{array}{l}0(0) \\
1(2)\end{array}$ & $\begin{array}{l}0(0) \\
0(0)\end{array}$ & $\begin{array}{c}4.62[\mathbf{0 . 7 3}] \\
4.58[0.76]\end{array}$ \\
\hline $\begin{array}{l}\text { Overall, I was satisfied } \\
\text { with the genetic counselor/ } \\
\text { doctor }\end{array}$ & $\begin{array}{l}\text { P } 53 \text { (84) } \\
V 45(82)\end{array}$ & $\begin{array}{l}7(11) \\
9(16)\end{array}$ & $\begin{array}{l}3(5) \\
0(0)\end{array}$ & $\begin{array}{l}0(0) \\
0(0)\end{array}$ & $\begin{array}{l}0(0) \\
1(2)\end{array}$ & $\begin{array}{l}0(0) \\
0(0)\end{array}$ & $\begin{array}{c}4.79[\mathbf{0 . 5 1}] \\
4.76[0.64]\end{array}$ \\
\hline $\begin{array}{l}\text { I would recommend this pro- } \\
\text { gram to a family member } \\
\text { or friend }\end{array}$ & $\begin{array}{l}\text { P } 50 \text { (79) } \\
\text { V } 45(82)\end{array}$ & $\begin{array}{c}11 \text { (17) } \\
7(13)\end{array}$ & $\begin{array}{l}2 \text { (3) } \\
1 \text { (2) }\end{array}$ & $\begin{array}{l}0(0) \\
0(0)\end{array}$ & $\begin{array}{l}0(0) \\
1(2)\end{array}$ & $\begin{array}{l}0(\mathbf{0}) \\
1(2)\end{array}$ & $\begin{array}{c}\mathbf{4 . 7 6}[\mathbf{0 . 4 9}] \\
4.76[0.67]\end{array}$ \\
\hline
\end{tabular}

time with the participant were each suggested by one respondent.

\section{Discussion}

The respondents' demographics parallel those of our overall participant population, although there is an overrepresentation of white respondents compared with participants (38\% and 23\%, respectively) and a corresponding underrepresentation of Hispanic respondents compared with participants (56\% and 74\%, respectively). That same trend was seen in preferred language, with $84 \%$ of respondents being primarily English speaking compared with $71 \%$ of participants, and with age, with $58 \%$ of respondents aged 50 years or older compared with $44 \%$ of participants. This difference might be explained by a greater degree of familiarity with clinical services and follow-up surveys in the white population. Civic disengagement, suspicion of purpose, and perceived social desirability of responses have been cited as possible explanations for survey nonresponse among minority and immigrant groups and may, in part, explain the lower response rate among our Hispanic participants. ${ }^{24} \mathrm{~A}$ greater proportion of respondents were aged 50 years or older $(58 \%)$ compared with the program participant population (44\%). Previous studies have found equivalent or superior response rates among Hispanics older than 50 years compared with whites in the same age group. ${ }^{25}$ Possible explanations for lower response rates in the older-than-50 age group include lack of a web-based survey and greater work or family obligations.

The survey itself is not expected to have been a factor in low response among the Hispanic participants because it was provided in English and Spanish. Respondents were slightly more likely to have undergone genetic testing than were participants ( $80 \%$ vs $69 \%$, respectively). There were no statistically significant differences across demographic factors and satisfaction with the program because of limited sample size.

Overall participant satisfaction with the program was very high. Multiple respondents expressed gratitude for the program and its associated services: 
The counseling experience was so incredibly valuable though it was months ago, I still carry pieces of the experience with me. [lt] helped me to recognize that testing impacts not only my life, but the lives of those connected to me genetically. [lt] made the decision feel so much more manageable.

It was a very good experience for me. They took care of me, and the secretary and the doctor treated me as someone very important to them.

Many participants were highly concerned about their cancer risk and other risk factors for cancer. An appreciable percentage of our participant population reported a history of agricultural labor and inquired about possible cancer risks as a result of environmental exposures, including pesticides. Financial barriers to needed preventative care and screening tests also increased participants concern for cancer. The program office received many calls from average-risk individuals requesting screening services, such as mammography or colonoscopy. When specifically surveyed about their perceived cancer risk, nearly half of the respondents reported a decreased perception of cancer risk following genetic counseling, which was also mirrored in the open-text comments:

If it wasn't for this program and the wonderful genetic counselor I met with, I would still be facing each day with fear.

These results gave me peace of mind. Before the testing, [1] was concerned that my children and grandchildren were at risk of [developing] cancer due to a genetic link.

These findings are similar to previous research regarding perception of cancer risk and anxiety following genetic counseling. ${ }^{26,27}$

In all, $16 \%$ of of the participants were found to harbor a pathogenic mutation in a cancer predisposing gene, and a variant of uncertain significance was identified in another $10 \%$ of participants. In addition to GCRA, participants who required baseline screening mammograms or colonoscopies or diagnostic imagining were navigated to community partners that provided the service. Another 16\% of respondents reported not knowing if their personal cancer risk was higher or lower than they believed it to be before their genetic counseling appointment. That may be due, in part, to pending genetic test results at the time of the survey. Other possible explanations include a lack of understanding of the information provided or discordance between the information provided and personal beliefs about cancer risk.
A request for more outreach and dissemination of program information was observed through the survey instrument and personal communication with participants during appointments. The program performed outreach and education at community health fairs, patient advocacy events, television, radio, newspaper interviews, and through direct education to health care providers. The program staff used NCCN and National Society of Genetic Counselors eligibility criteria to identify appropriate candidates for genetic counseling. Our program was limited to high-risk individuals, so a large number of average-risk individuals were not offered appointments. Finally, frequent reports about a lack of awareness of these services highlight the importance of family health history screening, education of primary care providers, and methods for appropriate referrals from primary care offices.

We did not bill for counseling services although telemedicine is a variably reimbursable service in many states. The option of telemedicine through video-conferencing saved provider costs that otherwise would have involved travel time to distant clinical sites as well as travel and time savings for patients.

\section{Implications of findings}

The acceptability of telemedicine genetic services by patients is widely documented. ${ }^{28,29}$ Our survey supports the previous literature with emphasis on a primarily minority population in a medically underserved region with no measurable differences in satisfaction between participants seen in-person or by video-teleconferencing. The border areas of Texas to date have scant access to cancer genetic counseling, but the use of video-conferencing has facilitated access to the service, overcoming one of the barriers to access because of distance. However, although our telegenetic services were able to bridge a service gap in this region, the fragmentation of families and medical care remains a barrier to access. Cascade testing in mutation-positive families is challenged by inaccessibility of genetic counseling or testing or travel limitations for those family members residing across the Texas-Mexico border. The verification of past medical history is limited by language barriers, underuse of health services, a lack of information about previous medical care, the separation of support systems, and difficulties collaborating with medical professionals outside the country. In addition, health literacy is the single best social determinant of an individual's health status, so the need for improved health literacy and the availability of health education material developed with cultural appropriateness and readability is a pressing concern. ${ }^{30}$

The findings of our survey demonstrate the acceptability of a cancer genetic risk assessment program heavily reliant on telemedicine in an underserved minority community. Despite the challenges previously noted in the literature about serving minority populations and barriers to 
cancer genetic risk assessment for Hispanics, we were able to provide these services in line with traditional genetic counseling services while maintaining a high level of participant satisfaction. As demand for genetic counselors continues to increase across the country, it is unreasonable to anticipate access to cancer genetic services in all nonmajor metropolitan areas. Incorporating similar programs in underserved areas may be an effective way of eliminat-

\section{References}

1. Center for Disease Control. Cancer among women. http://www.cdc. gov/cancer/dcpc/data/women.htm. Last updated August 20, 2015. Accessed March 28, 2016.

2. Kurian AW, Fish K, Shema SJ, Clarke CA. Lifetime risks of specific breast cancer subtypes among women in four racial/ethnic groups. Breast Cancer Res. 2010;12:R99.

3. American Cancer Society. Cancer Facts \& Figures for Hispanics/ Latinos 2012-2014. Atlanta: American Cancer Society, 2012. Accessed March 28, 2016.

4. Freedman RA, He Y, Winer EP, Keating NL. Racial/ethnic differences in receipt of timely adjuvant therapy for older women with breast cancer: are delays influenced by the hospitals where patients obtain surgical care? Health Serv Res. 2013;48:1669-1683.

5. Halpern MT, Ward EM, Pavluck AL, et al. Association of insurance status and ethnicity with cancer stage at diagnosis for 12 cancer sites: a retrospective analysis. Lancet Oncol. 2008;9:222-231.

6. Iqbal J, Ginsburg O, Rochon PA, Sun P, Narod SA. Differences in breast cancer stage at diagnosis and cancer-specific survival by race and ethnicity in the United States. JAMA. 2015;313:165-173.

7. Hampel H, Frankel WL, Martin E, et al. Feasibility of screening for Lynch syndrome among patients with colorectal cancer. J Clin Oncol. 2008;26:2783-5788.

8. NCCN. Clinical Practice Guidelines in Oncology. Genetic/Familial High-Risk Assessment: Colorectal. Version 2.2015. http://www. nccn.org/professionals/physician_gls/pdf/genetics_colon.pdf. Last updated February 2015. Accessed March 28, 2016.

9. Almario CV, May FP, Ponce NA, Spiegel BM. Racial and ethnic disparities in colonoscopic examination of individuals with family history of colorectal cancer. Clin Gastroenterol Hepatol. 2015;13:1487-1495.

10. Decker KM, Singh H. Reducing inequities in colorectal cancer screening in North America. J Carcinog. 2014;13:12.

11. Ojinnaka CO, Choi Y, Kum HC, Bolin JN. Predictors of colorectal cancer screening: does rurality play a role? J Rural Health. 2015;31:254-268.

12. Texas Center for the Advancement of Literacy \& Learning (TCALL). Percentage by country of illiterate adult Texans. http:// www-tcall.tamu.edu/docs/09illitmap.html. Last update 2009. Accessed March 26, 2015.

13. Texas Quick Facts. United States Census Bureau website. www.census.gov. Updated July 1, 2014. Accessed March 26, 2016.

14. The South Texas Health Status Review: a health disparities roadmap. Ed: Ramirez AG, Thompson IM, Vela L. San Antonio, Texas: University of Texas Health Science Center at San Antonio; 2013.

15. National Comprehensive Cancer Network. Clinical practice guidelines in oncology. Genetic/familial high-risk assessment: breast and ovarian. Version 2. http://www.nccn.org/professionals/physician_ gls/pdf/genetics_screening.pdf. Last updated 2014. Accessed March 26, 2016.

16. US Preventative Services Task Force. Risk assessment, genetic counseling, and genetic testing for BRCA-related cancer in women: U.S. ing disparities in access to services, and hopefully, in helping to decrease cancer burden in these populations.

\section{Acknowledgments}

The authors gratefully acknowledge the work of their community health workers, Norma Esquivel, Sonia Gomez, and Elena Marin; program assistants, Juliana Lopez and Carla Martinez; database coordinator Kristin Shelby; and the many providers and clinical collaborators in the South Texas community who worked with them on this project.

Preventative Services Task Force Recommendation statement. Ann Intern Med. 2014;160:271-281.

17. Kaufman B, Shapira-Frommer R, Schmutzler RK, et al. Olaparib monotherapy in patients with advanced cancer and a germline BRCA1/2 mutation. J Clin Oncol. 2014;33:244-250.

18. Isakoff SJ, Mayer EL, He L, et al. TBCRC009: A Multicenter phase II clinical trial of platinum monotherapy with biomarker assessment in metastatic triple-negative breast cancer. J Clin Oncol. 2015;33:1902-1909.

19. Gammon AD, Rothwell E, Simmon R, et al. Awareness and preferences regarding $\mathrm{BRCA} 1 / 2$ genetic counseling and testing among Latinas and non-Latina white women at increased risk for hereditary breast and ovarian cancer. J Genet Couns. 2011;20:625-638.

20. Glenn BA, Chawla N, Bastani R. Barriers to genetic testing for breast cancer risk among ethnic minority women: an exploratory study. Ethn Dis. 2012;22:267-273.

21. Sussner KM, Jandorf L, Thompson HS, Valdimarsadottir HB. Barriers and facilitators to BRCA genetic counseling among at-risk Latinas in New York City. Psychooncology. 2013;22:1594-1504.

22. D’Agincourt-Canning L, McGillivray B, Panabaker K, et al. Evaluation of genetic counseling for hereditary cancer by videoconference in British Columbia. BC Med J 2008;50:554-559.

23. DeMarco TA, Peshkin BN, Mars BD, Tercyak KP. Patient satisfaction with cancer genetic counseling: a psychometric analysis of the genetic counseling satisfaction scale. Journal of Genet Couns. 2004;13:293-304

24. Sheldon H, Graham C, Pothecary N, Rasul F. Increasing response rates amongst black and minority ethnic and seldom heard groups. http://www.nhssurveys.org/survey/525. Published March 2007. Accessed March 29, 2016.

25. Ofstedal MB, Weir DR. Recruitment and retention of minority participants in the health and retirement study. Gerontologist. 2011;51:S8-S20.

26. Pieterse AH, Ausems MGEM, Spreeuwenberg P, van Dulmen S. Longer-term influence of breast cancer genetic counseling on cognitions and distress: smaller benefits for affected versus unaffected women. Patient Educ Couns. 2011;85:425-431.

27. Rentala J, Platten U, Lindgren G, et al. Risk perception after genetic counseling in patients with increased risk of cancer. Hered Cancer Clin Pract. 2009;7:15.

28. Hilgert JS, Hayward JA, Coles B, Iredale R. Telegenetics: a systematic review of telemedicine in genetics services. Genet Med. 2012;14:765-766.

29. McDonald E, Lamb A, Grillo B, Lucas L, Miesfeldt S. Acceptability of telemedicine and other caner genetic counseling models of service delivery in geographically remote settings. J Genet Couns. 2014;23:221-228.

30. Berkman ND, Sheridan SL, Donahue KE, Halpern DJ, Crotty K. Low health literacy and health outcomes: an updated systematic review. Ann Intern Med. 2011;155:97-107. 